ОПЫТ ПРИМЕНЕНИЯ ИГЛ С РАЗЛИЧНЫМИ ТИПАМИ НАКОНЕЧНИКОВ ДЛЯ ПРОВЕДЕНИЯ СПИНАЛЬНЫХ И ЭПИДУРАЛЬНЫХ АНЕСТЕЗИЙ В УСЛОВИЯХ ПЕРИНАТАЛЬНОГО ЦЕНТРА ГОРОДА РЯЗАНИ

(C) А.В. Озеров, Н. Вагхулде, Е.В. Пимахина, Н.Г. Ершов

Рязанский государственный медицинский университет имени академика И.П. Павлова, г. Рязань, Российская Федерация

Цель исследования. Повышение безопасности эпидуральной и спинальной анестезий, снижение частоты, профилактика постпункционной головной боли у рожениц.

Материалы и методы. Проанализированы данные 180 женщин в возрасте от 19 до 42 лет, которым выполнялась эпидуральная или спинальная анестезия во время операции «извлечение плода из полости матки». Рожениц разделили на 2 группы: в 1 (60 женщин) использовались иглы типа Квинке, во 2 (120 женщин) анестезию выполняли иглами типа Уитакара с заточкой «pencil-point». Критерием включения в исследование было отсутствие сопутствующих заболеваний и патологий беременности, кроме анатомической узости родового канала, делающей невозможной родоразрешение через естественные родовые пути.

Результаты. Установлено, что при применении игл с острием типа Квинке в $30 \%$ случаев возникала постпункционная головная боль. Механизм данного осложнения мы связываем с нарушением целостности твёрдой мозговой оболочки. Это приводит к истечению ликвора и снижению давления спинномозговой жидкости. Для уменьшения отрицательных эффектов предложена авторская методика введения коллоидных и кристаллоидных препаратов в сочетании с кофеином.

Выводы. Для уменьшения осложнений на фоне проведения спинальных и эпидуральных анестезий в акушерской практике предпочтительно использование игл с заточкой типа pencilpoint. В случае развития в послеоперационном периоде осложнений в виде нарушения приспособительных вазомоторных реакций, рекомендовано использование кристаллоидов и коллоидов в сочетании с кофеином по авторской методике.

Ключевые слова: постпункиионный синдром, постпункиионная головная боль, эпидуральная анестезия, спинальная анестезия, полиглюкин, кофеин, беременность.

\title{
EXPERIENCE OF USING NEEDLES WITH DIFFERENT TYPES OF TIPS FOR PERFORMING SPINAL AND EPIDURAL ANESTHESIA IN THE ENVIRONMENT OF THE PENINATAL CENTER OF THE CITY OF RYAZAN
}

\author{
(C) A.V. Ozerov, N. Waghulde, E.B. Pimachina, N.G. Ershov
}

Ryazan State Medical University, Ryazan, Russian Federation

Aim. The aim of the study was to increase the safety of epidural and spinal anesthesia, reduce the frequency, prevention of post-operative headache in women in labor.

Materials and Methods. The data of 180 women aged 19 to 42 years who underwent epidural or spinal anesthesia during the operation «fetal extraction from the uterine cavity» were ana- 
lyzed. Parturient women were divided into 2 groups: 1 (60 women) used Quincke-type needles, 2 (120 women) performed anesthesia with Whitacar-type needles with «pencil-point» sharpening.The criterion for inclusion in the study was the absence of concomitant diseases and pathologies of pregnancy, except for the anatomical narrowness of the birth canal, making it impossible to deliver through the natural birth canal.

Results. It was found that the use of needles with a Quincke type in $30 \%$ of cases there was a post-puncture headache. The mechanism of this complication we associate with the violation of the integrity of the dura mater. This leads to the expiration of liquor and reduce the pressure of cerebrospinal fluid. To reduce the negative effects of the proposed author's method of administration of colloidal and crystalloid drugs in combination with caffeine.

Conclusion. To reduce complications during spinal and epidural anesthesia in obstetric practice it is preferable to use needles with sharpening of «pencil-point» type. In the case of postoperative complications in the form of violations of adaptive vasomotor reactions, it is recommended to use crystalloids and colloids in combination with caffeine by the author's method.

Keywords: post-lumbar puncture headache, epidural needle, coffeine, rheopolyglucinum, pregnancy.

Эпидуральная и спинальная анестезии - наиболее распространённый вид обезболивания в акушерской практике. Сегодня это золотой стандарт при обезболивании в акушерской практике [1]. Технично выполненное обезболивание очень важно в сохранении жизни и здоровья матери и ребенка [2].

На текущий момент при выполнении эпидуральной и спинальной анестезий наиболее широко используются два типа игл: Квинке и Уитакара.
Иглы с острием типа Квинке представляют режущий тип игл для спинальной анестезии, используются наиболее часто. Игла имеет средней длины срез с острыми краями, острым концом и отверстием на конце (Рис. 1 А). Оставляет в твёрдой мозговой оболочке (ТМО) резаное отверстие (Рис. 2 А-1, А-2). Популярность данного вида игл объясняется простотой манипуляции при спинальной пункции, дешевизной производства.
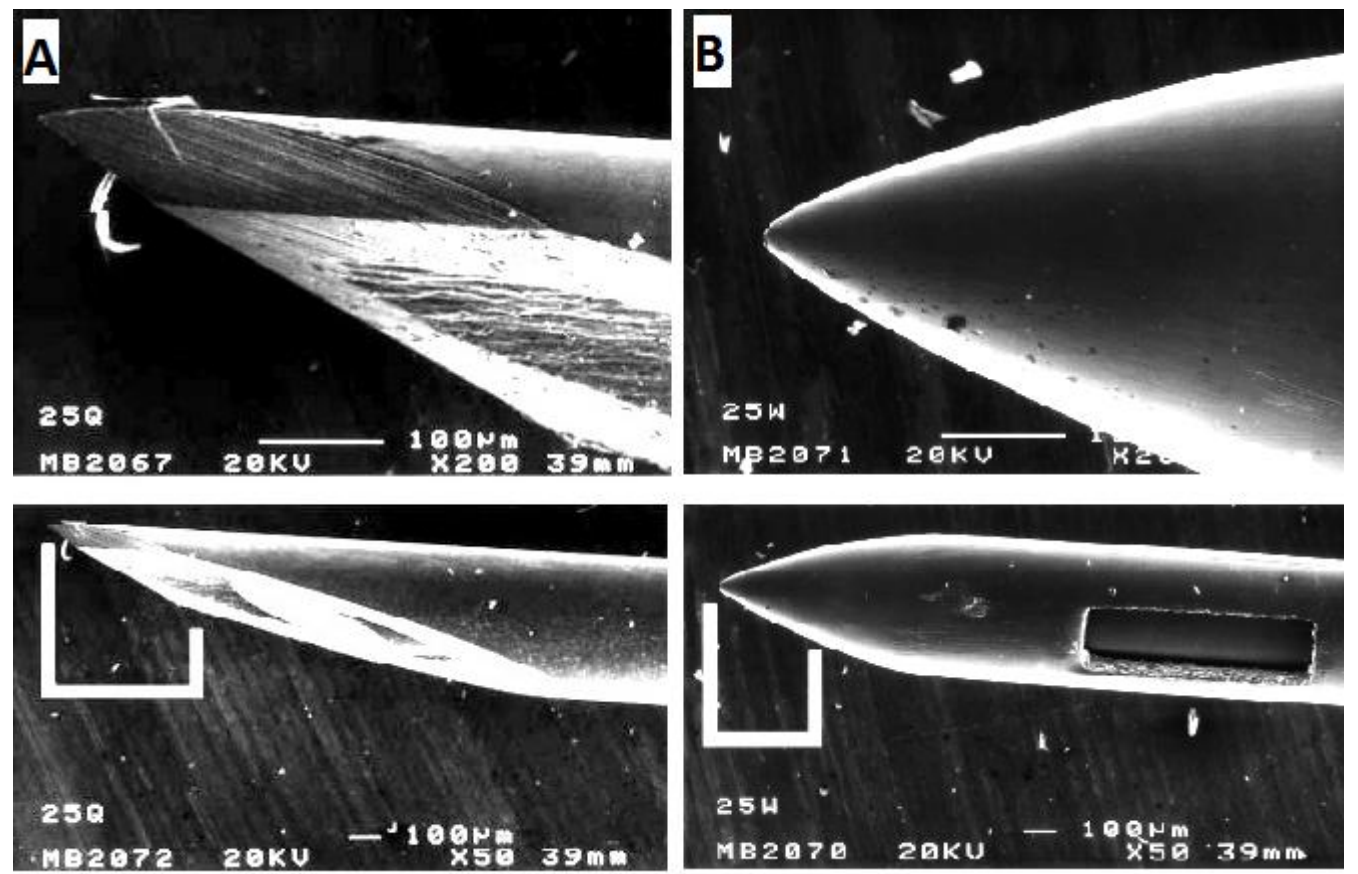

Рис. 1. Фотография колющей части игл Квинке и Уитакара [3] 
Иглы с острием Whitacre относятся к иглам с концом «карандашного типа» (англ. Pencil-point), рядом с острием иглы имеется боковое окно из которого истекает инъецируемая жидкость, что позволяет обеспечить направленное введение анестезирующего раствора.
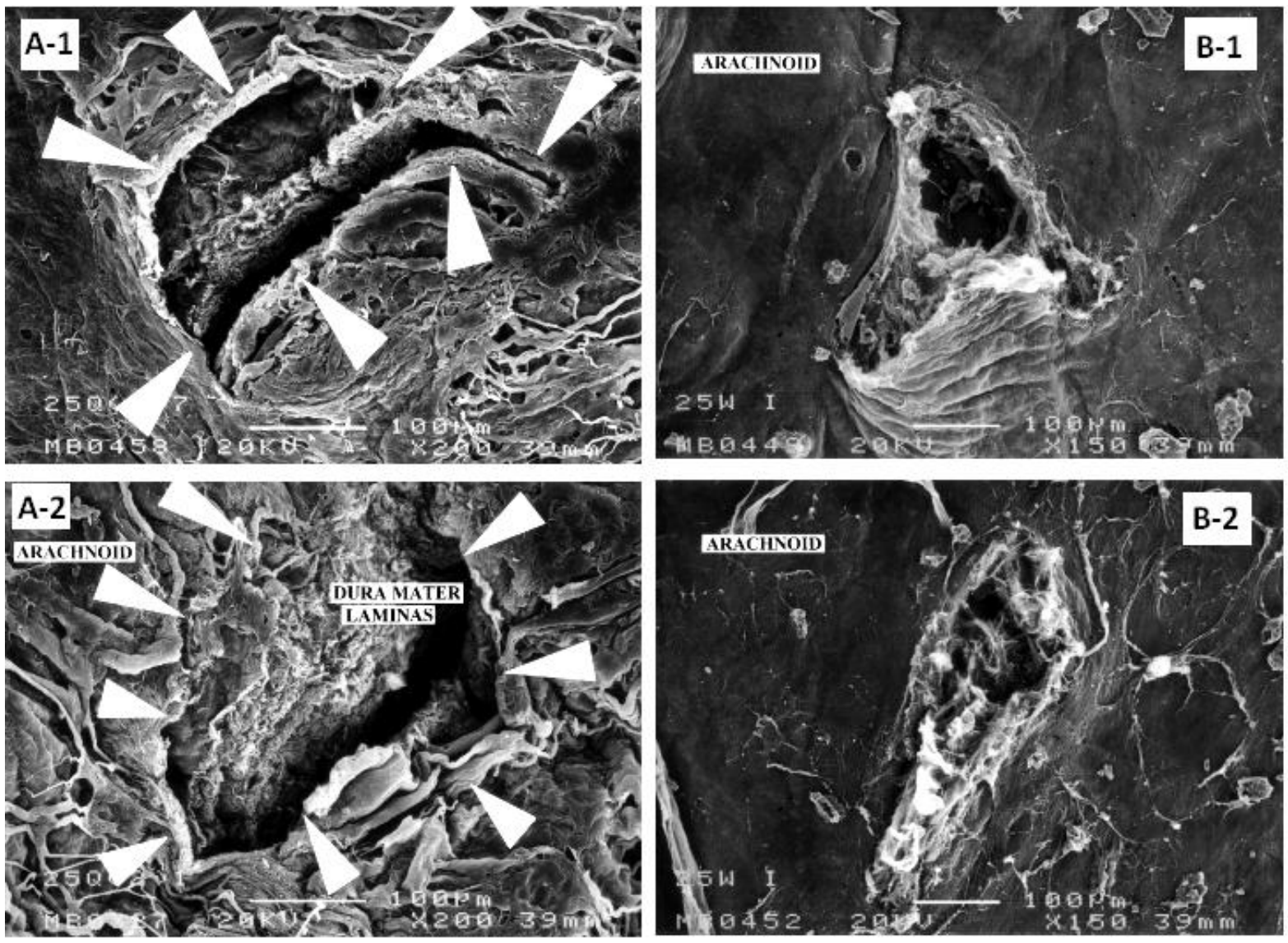

Коническая форма острия спинальной иглы без режущих граней обеспечивает атравматичное пунктирование ТМО, так как происходит не прорезывание, а раздвигание волокон ТМО, которые впоследствии быстрее восстанавливают герметичность спинномозгового канала (Рис. 2. В-1, В-2).

Рис. 2. Постпункционные отверстия в твёрдой мозговой оболочки от игл Квинке и Уитакара [3]

К сожалению, подобного рода манипуляция, проведённая иглами режущей заточки (иглы с острием типа Квинке), приводит к осложнениям в послеоперационном периоде в виде нарушений приспособительных вазомоторных реакций, так называемой постпункционной головной боли $[4,5]$.

\section{Цель исследования}

Повышение безопасности эпидуральной и спинальной анестезий, снижение частоты постпункционной головной боли (ППГБ) и профилактика данного осложнения у рожениц. 
проводили иглой типа Квинке. У 120 рожениц 2 группы использовали иглы типа Уитакара с заточкой «pencil-point».

Критерием включения в исследование было отсутствие сопутствующих заболеваний и патологий беременности, кроме анатомической узости родового канала, делающей невозможной родоразрешение через естественные родовые пути.

Полученные данные подвергали статистической обработке на персональном компьютере, с помощью пакета программ Excel 2015 с использованием статистических функций с вычислением среднеарифметической (M), среднего квадратичного отклонения $(\delta)$, стандартной ошибки (m), относительных величин (частота, \%), критерия Стьюдента (t) с вычислением вероятности ошибки (p). Различия средних величин считали достоверными при уровне значимости $p<0,05$. При анализе соблюдались указания по статистической обработке данных клинических и лабораторных исследований.

\section{Результаты и их обсуждение}

Частота возникновения ППГБ в 1 группе составила 18 человек, что составляет $30 \%$, в то время как во 2 группе частота возникновения ППГБ была 6 человек, что составляет $0,5 \%$.

Был изучен патогенез возникновения ППГБ, который развивается следующим образом. Пункционная игла нарушает целостность твёрдой мозговой оболочки, это приводит к истечению ликвора. Если место пункционного прокола относительно велико и не «склеивается» достаточно быстро, происходит истечение большого количества ликвора, падение давления спинномозговой жидкости (СМЖ).

Это ведёт к компенсаторному увеличению мозгового кровотока в результате дилатации интракраниальных вен, что вызывает раздражение твёрдой мозговой оболочки посредством активации болевых рецепторов. Это приводит к возникновению изучаемой симптоматике [6].

На основании этого было решено использовать полиглюкин в схеме инфузий у рожениц после проведения спинальной и эпидуральной анестезий (Рационализаторское предложение № 1382 «Применение полиглюкина в схеме инфузий у рожениц после проведения спинальной и эпидуральной анестезий» от 10.06 2016) [7].

Всем 18 женщинам с ППГБ на вторые сутки после операции последовательно внутривенно вводили следующие препараты - 500 мл $0,9 \%$ раствора хлорида натрия с 1,0 мл кофеина, 400 мл полиглюкина, 500 мл 0,9\% раствора хлорида натрия.

У всех женщин первой группы отмечали абсолютное исчезновение симптоматики ППГБ в день проведения инфузий по авторской методике.

Данный эффект был достигнут благодаря рациональной комбинации вводимых веществ, действующих на основные звенья патогенеза:

- кофеин, являясь стимулятором центральной нервной системы (ЦНС), приводит к развитию церебрального вазоспазма, что снижает раздражение рецепторов твёрдой мозговой оболочки;

- хлорид натрия восполняет объёма циркулирующей жидкости, а полиглюкин, являясь коллоидом, повышает коллоидноосмотическое давление в крови. Это положительно влияет на основное звено патогенеза, устраняя дефицит СМЖ.

\section{Выводы}

Для уменьшения осложнений на фоне проведения спинальных и эпидуральных анестезий в акушерской практике предпочтительно использование игл с заточкой типа pencilpoint. В случае развития в послеоперационном периоде осложнений в виде нарушения приспособительных вазомоторных реакций, рекомендовано использование кристаллоидов и коллоидов в сочетании с кофеином по авторской методике.

Дополнительная информация

Конфликт интересов: отсутствует. Участие авторов:

Иллюстрация статьи, обработка микроскопии данных - О.А.В.

Перевод статьи - В.Н.

Руководство проектом, организация исследовательской деятельности, проведение практиче- 
ских исследований на базе ГБУ РО «Областной Клинический Перинатальный Центр» - П.Е.В.
Научная и практическая консультация при ведении исследования - Е.Н.Г.

\section{Литература}

1. Ершов Н.Г., Павлов Г.В., Молостов В.С., и др. Анализ применения препарата ропивакаина гидрохлорида (наропина) фирмы Astra Zeneca при выполнении эпидуральных анестезий в гинекологии. В кн: Последипломное образование работников здравоохранения и современные проблемы медицины. Рязань: РязГМУ; 2007. С. 89-92.

2. Шурыгин И.А. Спинальная анестезия при кесаревом сечении. СПб.: Диалект; 2004.

3. De Leon Casasola O.A, Lopez A., Andres J., et al. An in vitro study of dural lesions produced by 25 Gauge Quincke and Whitacre needles evaluated by scanning electron microscopy // Regional Anesthesia and Pain Medicine. 2000. Vol. 25, №4. P. 393-402.

4. Малтабарова Н.А., Елеусизова А.В., Кадиков Ш.Ж., и др. Влияние типа спинальной иглы на развитие постпункционной головной боли. В сб.: Материалы международной заочной научнопрактической конференции «Наука и образование в современном мире»; 20 декабря 2016 г. Кишинев; 198-205.

5. Spielman F.J. Post-lumbar Puncture Headache // Headache: The Journal of Head and Face Pain. 1982. Vol. 22, №6. Р. 280-283.

6. Небылицин Ю.С., Славников А.В., Ивец И.Л. Постпункционная головная боль // Наука молодых (Eruditio Juvenium). 2018. T. 6, №2. C. 308-317.

7. Пимахина Е.В., Нойкин С.В. Применение полиглюкина в схеме инфузий у рожениц после проведения спинальной и эпидуральной анестезий. В сб.: Материалы ежегодной научной конференции Рязанского государственного медицинского университета имени академика ИП Павлова «Ежегодная научная конференция Рязанского государственного медицинского университета имени академика ИП Павлова, посвящённая 65-летию работы университета на Рязанской земле»; 18 декабря 2015 г. Рязань; 52-53.

\section{References}

1. Ershov NG, Pavlov GV, Molostov VS, et al. Analiz primeneniya preparata ropivakaina gidrokhlorida (naropina) firmy Astra Zeneca pri vypolnenii epidural'nykh anesteziy v ginekologii. Poslediplomnoe obrazovanie rabotnikov zdravookhraneniya i sovremennye problemy meditsiny. Ryazan: RSMU; 2007;89-92. (In Russ).

2. Shurygin IA. Spinal'naya anesteziya pri kesarevom sechenii. SPb.: Dialekt; 2004. (In Russ).

3. De Leon Casasola OA, Lopez A, Andres J, et al. An in vitro study of dural lesions produced by 25 Gauge Quincke and Whitacre needles evaluated by scanning electron microscopy. Regional Anesthesia and Pain Medicine. 2000;25(4):393-402. doi:10.1097/00132582-200020040-00015

4. Maltabarova NA, Eleusizova AV, Kadikov SZ, et al. Vliyanie tipa spinal'noj igly na razvitie postpunkcionnoj golovnoj boli. In: Materialy mezhdunarodnoj zaochnoj nauchno-prakticheskoj konferencii: Nauka i obrazovanie v sovremennom mire; 20 Dec 2016; Kishinev; 198-205. (In Russ).

5. Spielman FJ. Post-lumbar Puncture Headache. Headache: The Journal of Head and Face Pain. 1982;22(6):280-3. doi:10.1111/j.1526-4610.1982. hed2206280.x

6. Nebylicin YuS, Slavnikov AV, Ivets IL. Postdural puncture headache. Science of the young (Eruditio Juvenium). 2018;6(2):308-17. doi:10.23888/HMJ 20182308-317

7. Pimahina EV, Nojkin SV. Primenenie poliglyukina $\mathrm{v}$ skheme infuzij u rozhenic posle provedeniya spinal'noj i ehpidural'noj anestezij. In: Materialy ezhegodnoj nauchnoj konferencii Ryazanskogo gosudarstvennogo medicinskogo universiteta imeni akademika IP Pavlova: Ezhegodnaya nauchnaya konferenciya Ryazanskogo gosudarstvennogo medicinskogo universiteta imeni akademika IP Pavlova, posvyashchyonnaya 65-letiyu raboty universiteta na Ryazanskoj zemle; 18 Dec 2015; Ryazan'; 52-3. (In Russ).

\section{Информация об авторах [Authors Info]}

Озеров Андрей Владимирович - студент, Рязанский государственный медицинский университет им. акад. И.П. Павлова, г. Рязань, Российская Федерация.

SPIN: 3016-6311, ORCID ID: 0000-0001-8946-4589.

Andrey V. Ozerov - student, Ryazan State Medical University, Ryazan, Russian Federation.

SPIN: 3016-6311, ORCID ID: 0000-0001-8946-4589.

Вакхулде Нитишаа - студентка, Рязанский государственный медицинский университет им. акад. И.П. Павлова, г. Рязань, Российская Федерация.

SPIN: 2440-2286, ORCID ID: 0000-0001-5018-9524.

Waghulde Nitishaa - student, Ryazan State Medical University, Ryazan, Russian Federation.

SPIN: 2440-2286, ORCID ID: 0000-0001-5018-9524. 
Пимахина Елена Владимировна - к.м.н., ассистент кафедры факультетской хирургии с курсом анестезиологии и реаниматологии , Рязанский государственный медицинский университет им. акад. И.П. Павлова, г. Рязань, Российская Федерация. е-таil: elenapim@yandex.ru

SPIN: 6039-2619, ORCID ID: 0000-0001-7618-5273.

Elena V. Pimakhina - MD, PhD, assistant of the department of Faculty Surgery with the course of anesthesiology and intensive care, Ryazan State Medical University, Ryazan, Russian Federation. e-mail: elenapim@yandex.ru SPIN: 6039-2619, ORCID ID: 0000-0001-7618-5273.

Ершов Николай Георгиевич - к.м.н., доцент кафедры факультетской хирургии с курсом анестезиологии и реаниматологии, Рязанский государственный медицинский университет им. акад. И.П. Павлова, г. Рязань, Российская Федерация.

SPIN: 6142-3461, ORCID ID: 0000-0002-2858-519X.

Ershov Nikolai Georgievich - PhD, associate professor of the department of Faculty Surgery with the course of anesthesiology and intensive care, Ryazan State Medical University, Ryazan, Russian Federation. SPIN: 6142-3461, ORCID ID: 0000-0002-2858-519X.

Цитировать: Озеров А.В., Вагхулде Н., Пимахина Е.В., Ершов Н.Г. Опыт применения игл с различными типами наконечников для проведения спинальных и эпидуральных анестезий в условиях перинатального центра города Рязани // Наука молодых (Еruditio Јuvenium). 2018. T. 6, №3. C. 388-393. doi:10.23888/HMJ201863388-393

To cite this article: Ozerov AV, Waghulde N, Pimachina EB, Ershov NG. Experience of using needles with different types of tips for performing spinal and epidural anesthesia in the environment of the peninatal center of the city of Ryazan. Science of the young (Eruditio Juvenium). 2018;6(3):388-93. doi:10.23888/HMJ201863388-393

Поступила / Received: 06.12.2017

Принята в печать / Accepted: 30.08.2018 